\title{
Influence of Control Mechanism on the Flow field of Duct at Mach 1.2 for Area Ratio 2.56
}

\author{
S. A. Khan, Abdul Aabid, Zakir Ilahi Chaudhary
}

\begin{abstract}
In this paper, the outcome of the experimental investigation and the flow field development in the duct at supersonic Mach number of 1.2 is presented. The experiments were conducted at various NPR which covers the condition of correct expansion and under expansion. A Convergent-divergent (C-D) nozzle which is connected with the suddenly expanded duct of the diameter of $16 \mathrm{~mm}$ of area ratio 2.56 . The recirculation zone is controlled by using the microjets of $1 \mathrm{~mm}$ of orifice diameter which are placed at 90 degrees interval at $6.5 \mathrm{~mm}$ from the central axis of the main jet. The L/D of the duct was used in the investigation was from 1 to 10 , and the NPR at which the experiments were conducted considered are in the range from 3 , $5,7,9$ and 11.
\end{abstract}

Keywords-CD Nozzle; Microjet; Wall Pressure; and Mach number.

\section{INTRODUCTION}

Scholars in this field of external aerodynamics have long been concerned with the problem of sudden expansion at the blunt base of the projectiles, rockets, missiles, the fuselage of the aircraft, and the aircraft Bombs. The external compressible flow over the exhaust of the missiles/rockets and its relationship with the pressure at the base corner, and hence the resulting associated drag, which is a considerable portion of the net resistance of the aerodynamic body, is dictated by the low pressure at the blunt base which is usually sub-atmospheric. It is evident from the literature that the base pressure of high-speed missiles/rockets is lower than the ambient pressure, and how major results of ballistics test results have been shown that would give an impression that the base pressure in the wake region depends on the flight Mach number. Rathakrishnan and Khan have done considerable research in this field [1]-[4], they experimentally proved different conditions that can be used to characterize a suitable design of convergentdivergent (CD) nozzle which depends on Mach number and other essential parameters. The most important is the reduction of the effects of the base drag and to accomplish this we need to increase the base pressure in the recirculation zone of the base corner flow in the duct using the control mechanism as microjet.

Rehman et al. [5] experimentally investigated the base pressure control in a axisymmetric duct. They proved that wall pressure is not adversely influenced by the microjets as

Revised Manuscript Received on April 12, 2019.

S. A. Khan, Dept. of Mechanical Engineering Faculty of Engineering, International Islamic University, Kuala Lumpur, Malaysia, (Email: sakhan@iium.edu.my)

Abdul Aabid, Dept. of Mechanical Engineering Faculty of Engineering, International Islamic University, Kuala Lumpur, Malaysia.

Zakir Ilahi Chaudhary, Dept. of Automobile Engineering M H S S College of Engineering, Mumbai, India. a controller and they conducted the tests using the internal to simulate the supersonic flow. Airflow from C-D axisymmetric nozzles which is suddenly expanded into the circular duct of larger cross-sectional area than that of nozzle exit area is experimentally investigated, focused on the control of base pressure and the development of the flow in the enlarged duct. Their findings show that the control does not disturb the static wall pressure and the flow field in the duct. The control as tiny jets is able to reduce the base suction up to a great extent. The increment in the base pressure and hence the reduction in the base drag seems to be an immense help in the field of external aerodynamics [6]-[8]. The study on C-D nozzle with sudden expansion duct has been experimentally investigated by many authors [9] and proved that with the use micro jet we could control the base pressure in sudden expansion duct and not adversely influenced the wall pressure distribution.

Finite element method by ANSYS commercial software tool; some investigations have been found from last decades few of them are specified here. An ANSYS simulation was carried out to find out the effectiveness of microjets to regulate the pressure in base region for a two-dimensional convergent-divergent nozzle. The C-D nozzle geometry was modeled and simulated employing turbulence models; K- $\varepsilon$ standard wall function turbulence model from the code was independently checked with the commercial computational fluid dynamics [10]-[14] and optimized supersonic flow over the wedge [15].

The control of base pressure using microjet controller have been presented in the literature by the above authors and examined differences of the base pressure and wall pressure as a function of different parameters. Nevertheless, this has been done by changing one parameter at a time such as Mach number, L/D, Area ratio, and nozzle pressure ratio (NPR) although they interact. This investigation is aimed to improve the approach of data acquisition by measuring the wall pressure distribution and its effect on the nature of the flow. As a first step, we will take into consideration the Mach number $\mathrm{M}=1.2$, $\mathrm{L} / \mathrm{D}$ considered from 10 to 1 , Area ratio 2.56 and NPR 3 to 11. Experiments were also conducted for NPR's which are needed for correct expansion and under expansion. 


\section{INFLUENCE OF CONTROL MECHANISM ON THE FLOW FIELD OF DUCT AT MACH 1.2 FOR AREA RATIO 2.56}

\section{EXPERIMENTAL METHOD}

First, Experimental set up has been fabricated in such a way that to work as the projectile base. The pressure at the base area is the base pressure for projectiles and the geometrical variable is of paramount importance was the $\mathrm{L} / \mathrm{D}$ ratio of projectile divided by the parameter which is the ratio of inertia force to the viscous force. The major features of the flow field with sudden enlargement is shown in Figure 1.

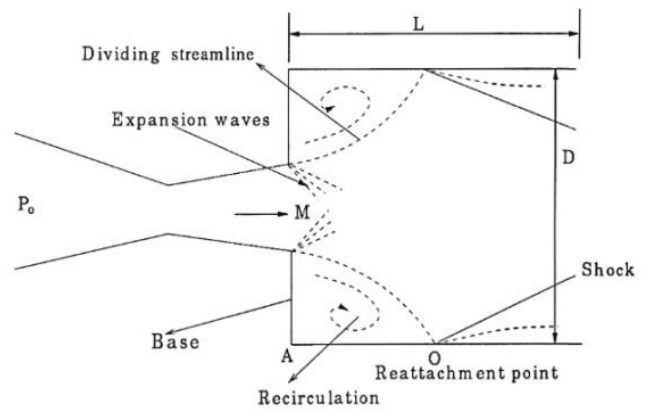

Figure 1: Flow Field with Sudden Expansion

Figure 2 illustrates the setup used for the experiments in the present study as discussed in Ref. [2].

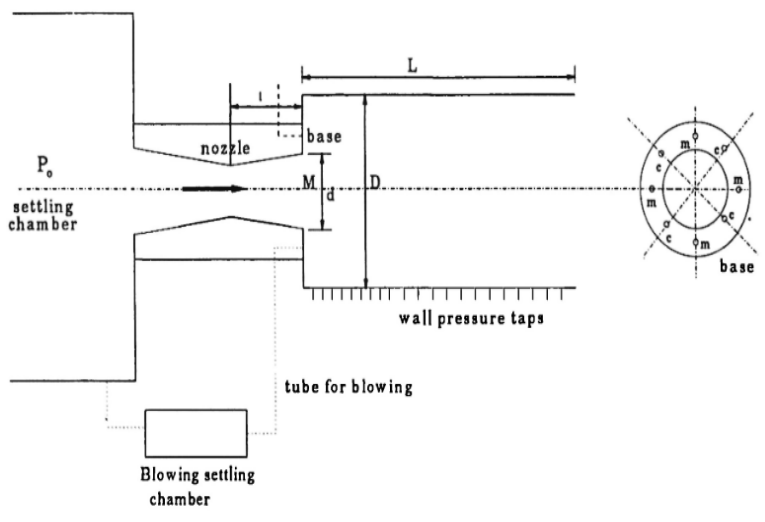

Figure 2: Experimental Setup.

\section{RESULTS AND DISCUSSION}

Before The nature of the flow in the duct was measured using the pressure transducer as discussed in Ref. [2] for M $=1.2$ and different level of expansion NPR and L/D ratio are shown in Figure 3 presents the wall pressure distribution in the enlarged duct for area ratio 2.56, for some selected combination of Inertia level. The measured wall pressure has been made non-dimensional with the atmospheric pressure $\mathrm{Pa}$ to which the flow was discharged. The axial distance of the enlarged duct from the base location $\mathrm{X}$ has been non-dimensionalized with the duct diameter D. To quantify the effect of control on wall pressure distribution $\mathrm{Pw} / \mathrm{Pa}$ for with and without control have been compared for entire range of NPR, inertia levels, and L/Ds tested at fixed Mach number and the relief to the flow.

The results show that, for $L / D=10$ and $M=1.2$ the control does not influence the wall pressure (as in the case of Figures. 3(a) or influences the wall pressure only marginally). Further, it is seen that for NPR 3 the fluctuations in the wall pressure are at its lowest level and they are limited within $10 \%$ distance from the exit of the nozzle, whereas for all the NPRs the flow field by itself is oscillatory in nature due the effect of area ratio, this area ratio being 2.56 lowest of the study, due to small relief available to the flow there will be inherent oscillatory nature of the flow and the control has only marginal effect on the flow field. The physics behind this trend seems to be due to the combined effect of the Mach number, NPR's (level of expansion), and the L/D ratio. A major contributor to this oscillatory nature is the lowest area ratio, which will be visible when we discuss the wall pressure distribution for other Mach numbers as well as the area ratio.

Figure 3 (b) presents similar wall pressure results for L/D $=8$ as was observed in the previous figure. Figures. 3((c) to (d)) represent the wall pressure results for $\mathrm{L} / \mathrm{D}=6$ and 5 with the exception that due to the reduction in the L/D ratio there is some influence of the back pressure and the peak wall pressure values are higher than that those were for higher $\mathrm{L} / \mathrm{D}$ ratios namely ( $\mathrm{L} / \mathrm{D}=10$ and 8) respectively. Nevertheless, the flow field has smoothened in the duct, and the wall pressure values with and without control are identical. This trend continues till $\mathrm{L} / \mathrm{D}=4,3$ and 2 (Figures. $3((\mathrm{e})$ to $(\mathrm{g}))$, then later for lowest $\mathrm{L} / \mathrm{D}$ like $\mathrm{L} / \mathrm{D}=1$, it is evident that length of the duct is not enough for the flow to remain attached with the duct and hence unable to create any suction in the base region hence we should not draw the inference.

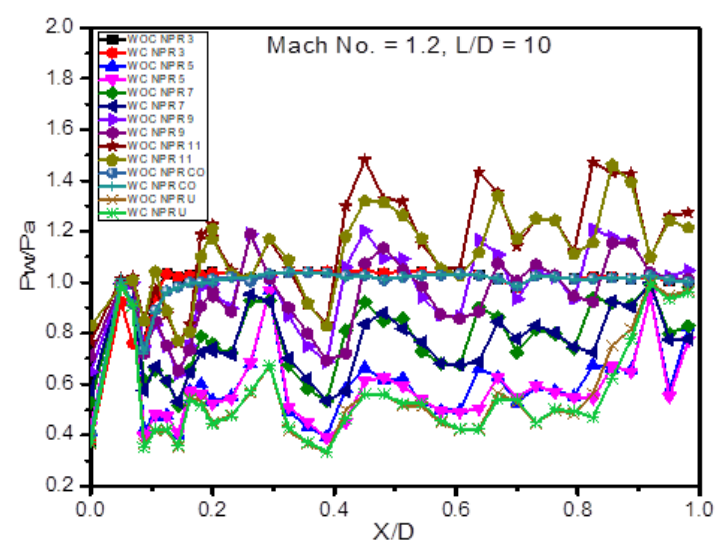

(a)

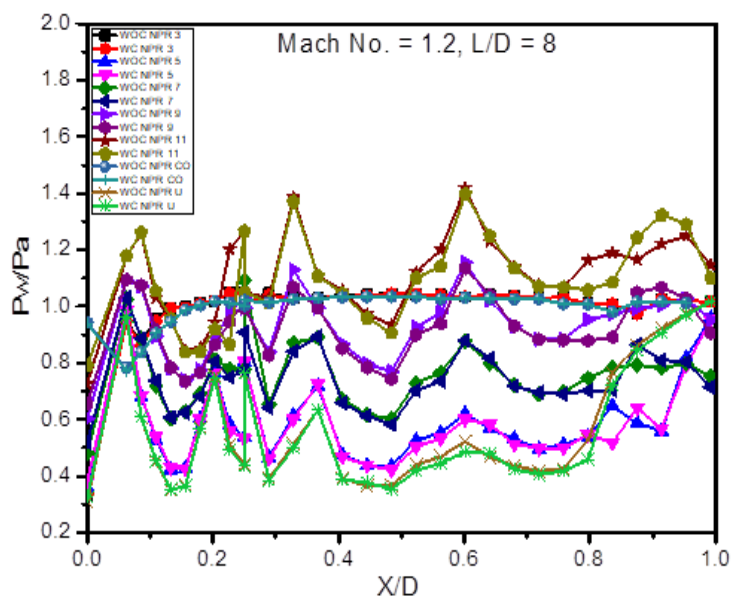

(b)

Published By: Blue Eyes Intelligence Engineering \& Sciences Publication 


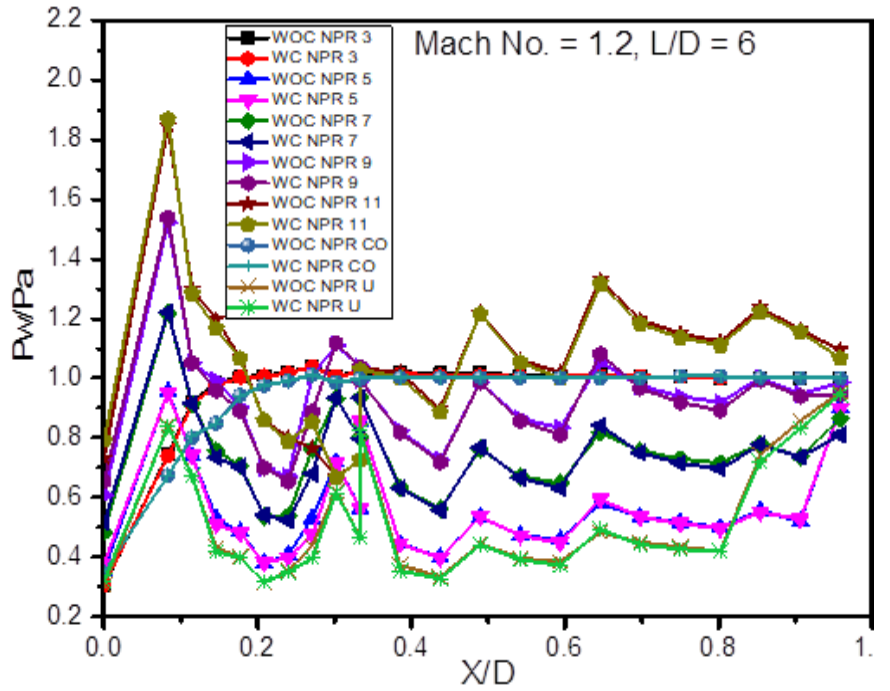

(c)

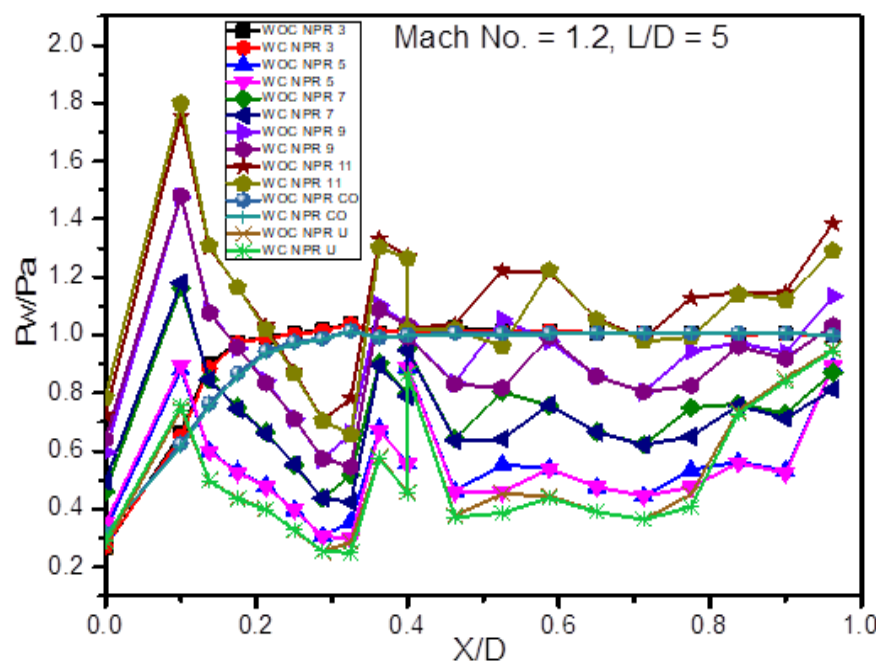

(d)

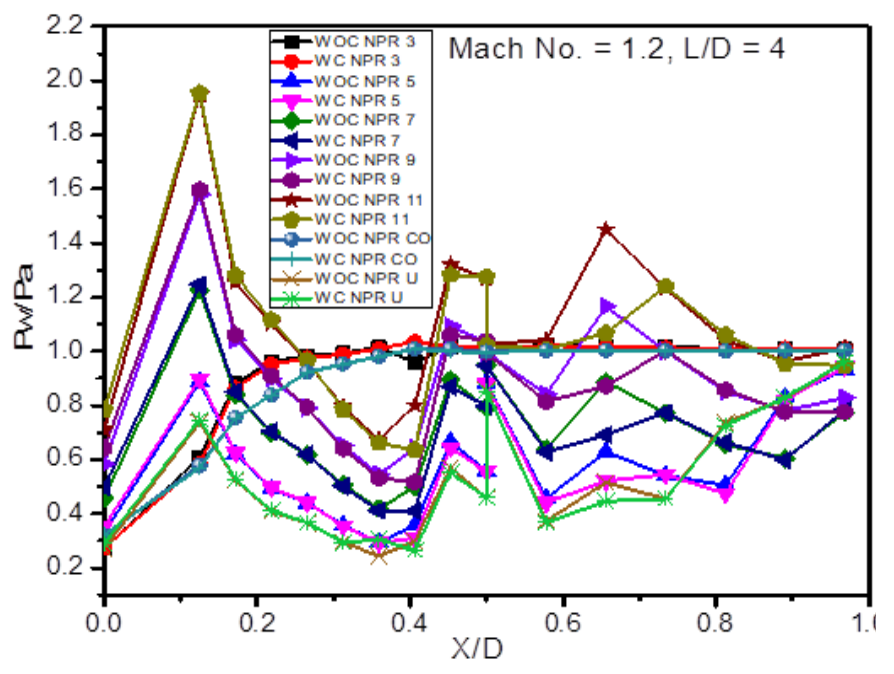

(e)

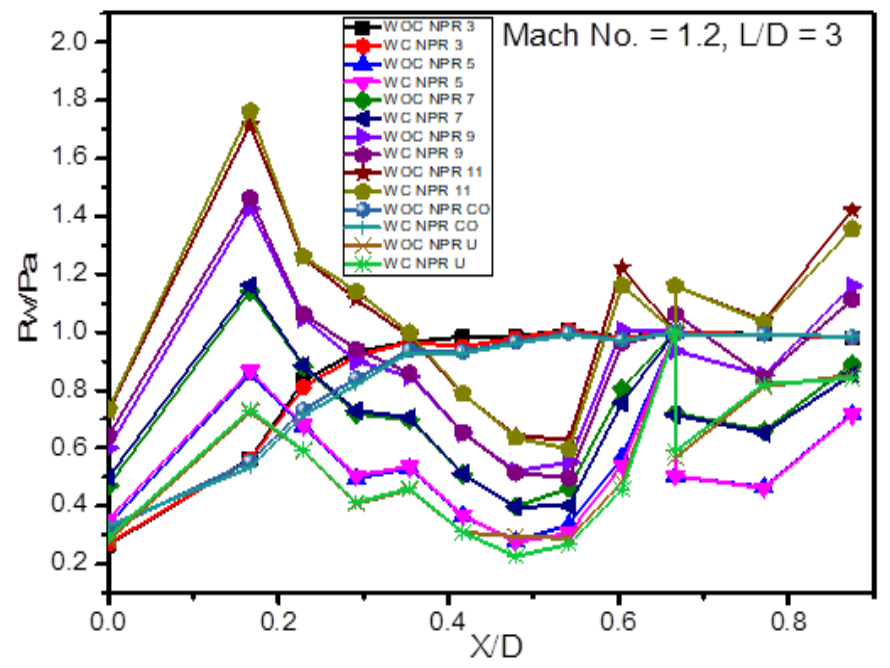

(f)

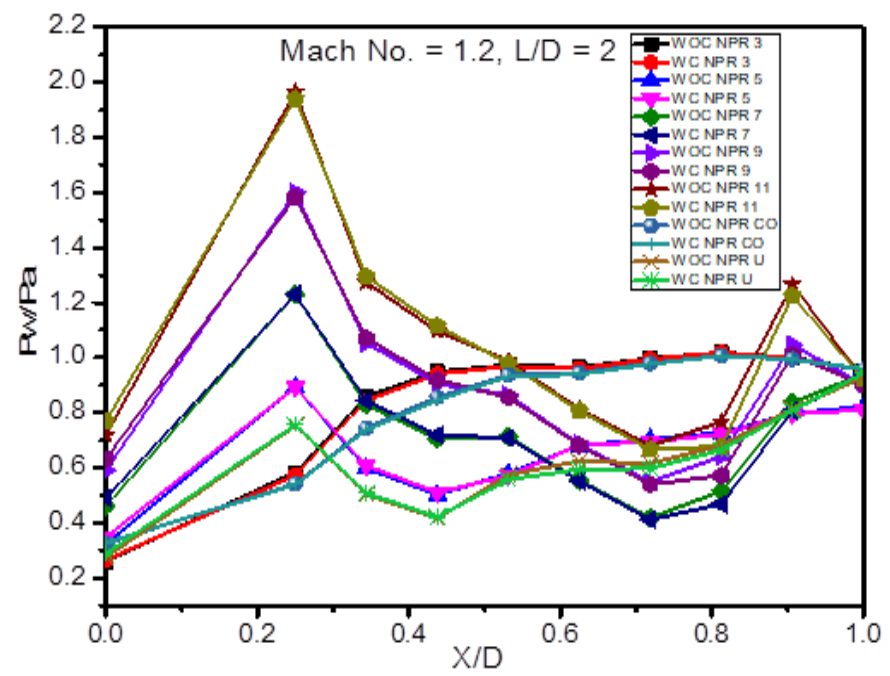

(g)

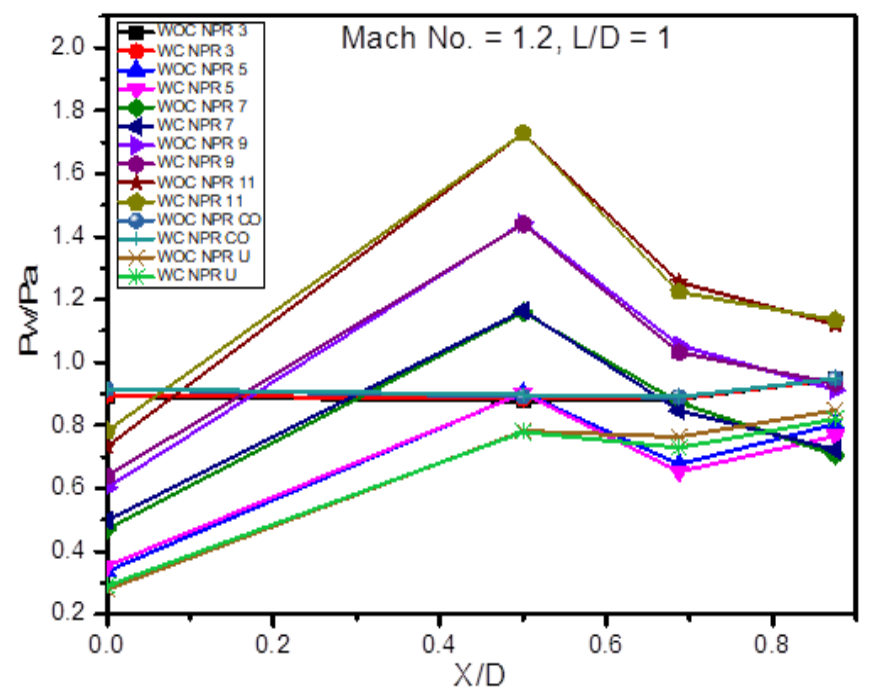

(h)

Figure 3: Wall pressure distribution

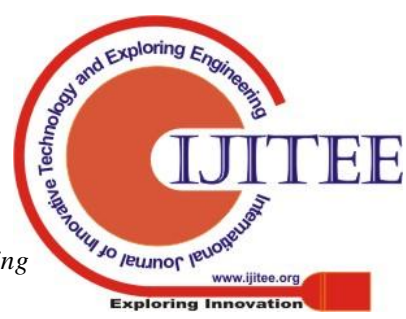




\section{INFLUENCE OF CONTROL MECHANISM ON THE FLOW FIELD OF DUCT AT MACH 1.2 FOR AREA RATIO 2.56}

\section{CONCLUSION}

The control of the base in the recirculation zone of the base corner and the flow field in the duct by microjets has been demonstrated. The wall pressure assumes a minimum for area ratio 2.56 and $\mathrm{L} / \mathrm{D}$ from 10 to 1 at Mach numbers 1.2. The microjets are found to be effective at this Mach number and area ratio 2.56 . The use microjets result in decrement of suction at the base and decrease of associated drag at these combinations of parameters, resulting in an 83 percent increase in base pressure. The duct wall pressure distribution is not adversely influenced by the active control.

\section{REFERENCES}

1. S. A. Khan and E. Rathakrishnan, "Control of Suddenly Expanded Flows with Micro-Jets," International Journal of Turbo and Jet Engines, vol. 20, pp. 63-82, 2003.

2. S. A. Khan and E. Rathakrishnan, "Control of Suddenly Expanded Flows from Correctly Expanded Nozzles," International Journal of Turbo and Jet Engines, vol. 21, pp. 255-278, 2004.

3. S. A. Khan and E. Rathakrishnan, "Active Control of Suddenly Expanded Flows from Underexpanded Nozzles," International Journal of Turbo and Jet Engines, vol. 21, pp. 233-254, 2004.

4. S. A. Khan and E. Rathakrishnan, "Active Control of Suddenly Expanded Flows from Overexpanded Nozzles," International Journal of Turbo and Jet Engines, vol. 19, pp. 119-126, 2002.

5. S. Rehman and S. A. Khan, "Control of base pressure with micro-jets: part I," Aircraft Engineering and Aerospace Technology, vol. 80, no. 2, pp. 158-164, 2008.

6. M. Ahmed and A. L. I. Baig, "Active control of base pressure in suddenly expanded flow for area ratio 4 .84," International Journal of Engineering Science and Technology, vol. 4, no. 05, pp. 1892-1902, 2012.

7. Z. Ilahi and S. A. Khan, "Investigation of base flow for an axisymmetric suddenly expanded nozzle with micro JET," International Journal of Engineering \& Technology, vol. 7, no. 3.29, pp. 236-242, 2018.

8. F. Ahmed and S. A. Khan, "Investigation of efficacy of low length-to-diameter ratio and nozzle pressure ratio on base pressure in an abruptly expanded flow," in MATEC Web of Conferences, 2018, no. January, p. 6.

9. S. A. Khan, M. Bashir, F. A. G. M, and M. A. Ullah, "An investigation of base flow control by wall pressure analysis in a suddenly expansion nozzle," Journal of Scientific Research and Development, vol. 3, no. 5, pp. 1-6, 2016.

10. A. Khan, A. Aabid, and S. A. Khan, "CFD analysis of convergent-divergent nozzle flow and base pressure control using micro-JETS," International Journal of Engineering and Technology, vol. 7, no. 3.29, pp. 232-235, 2018.

11. A. G. M. Fharukh, A. A. Alrobaian, A. Aabid, and S. A. Khan, "Numerical Analysis of Convergent-Divergent Nozzle Using Finite Element Method," International Journal of Mechanical and Production Engineering Research and Development, vol. 8, no. 6, pp. 373-382, 2018.

12. S. A. Khan, A. Aabid, and M. A. A. Baig, "CFD Analysis of CD Nozzle and Effect of Nozzle Pressure Ratio on Pressure and Velocity For Suddenly Expanded Flows," International Journal of Mechanical and Production Engineering Research and Development, vol. 8, no. June, pp. 1147-1158, 2018.

13. A. Aabid, A. Khan, N. M. Mazlan, M. A. Ismail, M. N. Akhtar, and S. A. Khan, "Numerical Simulation of Suddenly Expanded Flow at Mach 2.2," International Journal of Engineering and Advanced Technology, vol. 8, no. 3, pp. $457-462,2019$
14. S. A. Khan, A. Aabid, and C. A. Saleel, "Influence of Micro Jets on the Flow Development in the Enlarged Duct at Supersonic Mach number," International Journal of Mechanical and Mechatronics Engineering, vol. 19, no. 01, pp. 70-82, 2019.

15. S. A. Khan, A. Aabid, and C. A. Saleel, "CFD Simulation with Analytical and Theoretical Validation of Different Flow Parameters for the Wedge at Supersonic Mach Number," International Journal of Mechanical and Mechatronics Engineering, no. 01, 2019. 